\title{
Effect of hypoglycemia on measures of myocardial blood flow and myocardial injury in adults with and without type 1 diabetes: a prospective, randomized, open-label, blinded endpoint, cross-over study
}

Radzi M Noh ( $\square$ radzi.noh@doctors.org.uk)

Royal Infirmary of Edinburgh https://orcid.org/0000-0002-9814-5296

\section{AJ Graveling}

Royal Infirmary of Edinburgh

Ninian N Lang

The University of Edinburgh

Audrey C White

The University of Edinburgh

Ken K Lee

The University of Edinburgh

Nicholas L Mills

The University of Edinburgh

David E Newby

The University of Edinburgh

Chim C Lang

University of Dundee

Brian M Frier

Royal Infirmary of Edinburgh

Research article

Keywords: Cardiovascular function, Coronary Flow Reserve, Hypoglycemia, Myocardial Ischemia, Type 1 diabetes

Posted Date: June 2nd, 2020

DOl: https://doi.org/10.21203/rs.3.rs-31359/v1

License: (c) (1) This work is licensed under a Creative Commons Attribution 4.0 International License. Read Full License 


\section{Abstract}

Aims

Hypoglycemia provokes a profound autonomic response in humans including cardiovascular effects. This study examined the effect of experimentally-induced hypoglycemia on measures of myocardial blood flow and myocardial injury in adults with, and without, type 1 diabetes.

\section{Methods and Results}

In a prospective, randomized, open-label, blinded, endpoint cross-over study, 17 young adults with type 1 diabetes with no cardiovascular risk factors, and 10 healthy non-diabetic volunteers, underwent hyperinsulinemic euglycemic (blood glucose 4.5-5.5 mmol/L or 81-99 mg/dL) and hypoglycemic (2.2-2.5 $\mathrm{mmol} / \mathrm{L}$ or 40-45 mg/dL) clamps. Myocardial blood flow was assessed using transthoracic echocardiography Doppler coronary flow reserve (CFR) and myocardial injury using plasma highsensitivity cardiac troponin I (hs-cTnl) concentration. During euglycemia, a non-significant trend for lower CFR was observed in participants with type 1 diabetes than in those without type 1 diabetes (3.66 \pm 0.47 versus 3.92 \pm 0.85 ), and a non-significant lower trend also occurred during hypoglycemia (type 1 diabetes: $3.54 \pm 0.58$ versus non-diabetes: $3.80 \pm 0.84)$. A generalized linear mixed-model analysis was performed, with diabetes status and euglycaemia or hypoglycaemia as factors affecting CFR. No significant statistical difference in CFR was observed for diabetes status $(p=0.23)$ or between euglycemia and hypoglycemia $(p=0.31)$. No changes in hs-cTnl occurred during hypoglycemia or in the recovery period $(p=0.86)$.

\section{Conclusions}

While the observed reduction in coronary flow reserve did not achieve significance during exposure to insulin-induced hypoglycemia in healthy young men with type 1 diabetes, with no evidence of myocardial injury, adverse cardiovascular effects of hypoglycemia cannot be excluded in older people who have coronary disease. Further studies are required to investigate this putative problem.

\section{Background}

Diabetes is now a global pandemic (1) in which the principal cause of death is cardiovascular disease (2). While strict glycaemic control improves some outcomes, clinical trials in people with type 2 diabetes who have cardiovascular disease have shown that intensive glucose-lowering therapy is associated with a higher mortality $(3,4)$. It has been suggested that exposure to hypoglycemia may be contributing to this greater morbidity and mortality $(5,6)$.

Hypoglycemia is a common occurrence in people with insulin-treated diabetes. It causes profound autonomic stimulation leading to activation of the sympatho-adrenal system with profuse catecholamine release. This has pronounced systemic and regional hemodynamic effects (7), including large 
increments in stroke volume and cardiac output (8), caused by increased left ventricular ejection fraction and myocardial contractility (9). This augmented cardiac workload may provoke myocardial ischemia or cardiac failure in people who have established cardiac disease.

Mechanisms that could promote adverse effects of hypoglycemia on cardiovascular function have been proposed (10). Endothelial dysfunction is a key pathophysiological pathway underlying macrovascular complications in type 1 and type 2 diabetes. A detrimental effect of hypoglycemia on peripheral endothelial function has been reported (11). However, several differences exist between peripheral and coronary arterial endothelium, such as the presence of shunt vessels and the microvascular architecture (12). Direct measurement of coronary vasomotor function may therefore provide a more valid measure of any cardiovascular impairment resulting from limited vascular responsiveness. Measurement of coronary microvascular dysfunction by calculation of coronary flow reserve (CFR) is the preferred investigative technique (13). Coronary flow reserve measures the capacity of the coronary circulation to increase flow during maximal resistance vessel vasodilatation. Maximal hyperemia is achieved by intravenous infusion of adenosine (14) and coronary flow velocity can be measured non-invasively by transthoracic Doppler echocardiography $(15,16)$. CFR is reduced in people with type 1 diabetes during euglycemia (17) and in individuals with type 1 diabetes with evidence of microvascular disease in the form of retinopathy (18). It is unclear how hypoglycemia affects CFR.

Cardiac troponins are a biomarker of myocardial injury. In recent years, the introduction of a highly sensitive cardiac troponin I (hs-cTnl) assay allows detection of small degrees of myocardial damage. Lowering the diagnostic threshold for myocardial injury has improved outcomes for people with type 1 myocardial infarction (19). Hs-cTNI also provides prognostic information regarding long term outcomes in cohorts of people with underlying coronary artery disease (20).

People with type 2 diabetes often have multiple cardiovascular risk factors that can confound attempts to investigate hypoglycemia as a causative mechanism for cardiovascular morbidity and mortality. Younger people with type 1 diabetes of relatively short duration are less likely to have acquired these additional risk factors. To examine whether hypoglycemia might adversely affect myocardial blood flow and cause myocardial injury, coronary flow reserve and cardiac troponins were therefore measured during experimentally-induced hypoglycemia in people with type 1 diabetes who had no confounding factors.

\section{Materials And Methods}

\section{Study Participants}

Young healthy male adults with type 1 diabetes with no microvascular complications or cardiovascular risk factors were recruited from diabetes out-patient clinics in Lothian, Scotland. Men without diabetes, matched for age, were recruited by poster advertisements and from a database of volunteers. Only male subjects were studied to avoid the confounding effect of the variability of coronary flow reserve that occurs during the menstrual cycle (21). In addition, because the counterregulatory hormonal responses to 
hypoglycemia differ between men and women (22), the study was confined to men to avoid a potential effect of gender on the magnitude of the sympatho-adrenal stimulus during hypoglycemia.

Exclusion criteria included co-existent systemic disease, malignancy, chronic alcoholism, psychiatric disorder, any history of cardiac conduction abnormality, impaired awareness of hypoglycemia (as assessed by the method of Gold et al (23)), past history of severe hypoglycemia, and any evidence of overt microvascular complications including retinopathy and neuropathy or the presence of microalbuminuria.

A total of 17 male adults with type 1 diabetes and 10 age-matched individuals without diabetes were studied (Table 1). Participants with type 1 diabetes had reasonable glycemic control, (average glycated haemoglobin (HbA1c): $8.0 \pm 1.1 \% ; 64 \pm 11 \mathrm{mmol} / \mathrm{mol}$ ), with a median duration of diabetes of 15 years (range 2-35 years), which is consistent with average quality of glycemic control recorded in the adult population with type 1 diabetes in Scotland. The two groups of participants did not differ in age or bodymass index (Table 1).

The study was conducted with informed written consent of all subjects, the approval of the Lothian Medical Research Ethics committee, and in accordance with the Declaration of Helsinki.

\section{Study Design}

Participants attended for two study visits, performed on separate days at least two weeks apart to avoid any potential carry-over effects. Two experimental conditions, hypoglycemia (blood glucose $2.5 \mathrm{mmol} / \mathrm{L}$; $45 \mathrm{mg} / \mathrm{dL}$ ) and euglycemia $(4.5 \mathrm{mmol} / \mathrm{L} ; 81 \mathrm{mg} / \mathrm{dL})$, were studied in a prospective, randomised, openlabel, blinded endpoint, (PROBE) cross-over study. Both the group with type 1 diabetes and matched individuals underwent the experimental conditions, and then crossed-over. The order of the experimental method was randomized using alternate randomization by the operator of the glucose clamp, while the endpoint was blinded to the echocardiographer (Supplemental figure 1). This study design has been employed previously by our group (24), with modifications for the cardiovascular investigations.

Participants attended in a fasting state, having abstained from consumption of caffeine-containing food and beverages for 24 hours. Venous cannulae were inserted for intravenous infusion of dextrose and insulin, and blood sampling. A modified version of the hyperinsulinemic glucose clamp was employed (25). To arterialize blood samples, the non-dominant arm was wrapped in a heated blanket with a retrograde intravenous cannula inserted into the forearm. An additional cannula was inserted into the non-dominant antecubital fossa to infuse insulin (human Actrapid; Novo Nordisk, Crawley, U.K.) and 20\% dextrose. Insulin was infused at a constant rate of $1.5 \mathrm{mU} / \mathrm{kg} / \mathrm{min}$ with a Gemini PCl pump (Alaris Medical Systems, San Diego, CA). Blood samples were taken at 5-min intervals and analyzed by a glucose oxidase method (2300 STAT; YSI, Yellow Springs, OH). The dextrose infusion rate was adjusted to maintain the appropriate arterialized blood glucose concentration. During a run-in period, arterialized blood glucose was maintained at $4.5 \mathrm{mmol} / \mathrm{L}(81 \mathrm{mg} / \mathrm{dL})$ for $20 \mathrm{~min}$. Blood glucose was then either maintained at $4.5 \mathrm{mmol} / \mathrm{L}(81 \mathrm{mg} / \mathrm{dL})$ throughout (the euglycemia condition), or lowered over $20 \mathrm{~min}$ to 
$2.5 \mathrm{mmol} / \mathrm{L}$ (45 mg/dL) (the hypoglycemia condition), and maintained at this level for $30 \mathrm{~min}$ before restoration of euglycaemia. During the glucose clamp, the participants underwent an ultrasound examination by a trained ultrasound operator, using a well-described technique $(16,21)$. The timepoints were labelled as baseline, experimental (either euglycemia or hypoglycemia-blinded to the sonographer), and recovery (Supplemental Figure 1). Continuous electrocardiographic monitoring and regular blood pressure monitoring were performed throughout the study.

\section{Coronary Flow Velocity Measurements}

During each study condition, the left anterior descending coronary artery was visualized by trans-thoracic echocardiography. Transthoracic Doppler echocardiography was used for a non-invasive estimation of coronary flow velocity (CFV), and maximal coronary vasodilatation was induced with an adenosine infusion to allow calculation of CFR. Imaging of the left anterior descending (LAD) artery and measurement of coronary blood flow velocity was performed using a $7.0 \mathrm{MHz}$ transducer (Acuson Sequoia 512, Siemens Medical Solutions, Berkshire, UK). Baseline spectral Doppler signals were recorded initially in the distal portion of the LAD coronary artery over five cardiac cycles at end-expiration. To measure coronary flow reserve (CFR), intravenous adenosine was administered $(0.14 \mathrm{mg} / \mathrm{kg} / \mathrm{min}$; Adenocor, Sanofi) for up to 4 min to record spectral Doppler signals during hyperemic conditions (14). Coronary velocities were measured at baseline and at peak hyperemic conditions from the Doppler signal recordings. Measurements were averaged over three cardiac cycles. CFR was defined as the ratio of hyperemic to basal velocities, using maximum velocity (Vmax) parameters (Supplemental Figure 2). Blood pressure was recorded at baseline, during adenosine infusion and at recovery. CFR was calculated at baseline, during the experimental phase (0-20 $\mathrm{min})$ and in the recovery phase.

\section{High-sensitivity Cardiac Troponin I Concentration}

Blood samples were taken prior to assessment of CFR, during the experimental hyperinsulinemic clamp, and during the recovery period (Supplemental Figure 1). High-sensitivity cardiac troponin I concentrations were determined using the ARCHITECT STAT high-sensitive troponin I assay (Abbott Laboratories, Abbott Park, IL). This is the first clinically approved high-sensitivity troponin I assay, which has excellent precision at very low concentrations. The limit of detection is $1.2 \mathrm{ng} / \mathrm{L}$ and precision profiling in our laboratory has demonstrated an inter-assay coefficient of variation (CV) of $<10 \%$ at $5 \mathrm{ng} / \mathrm{L}$. The upper reference limit or $99^{\text {th }}$ centile is $16 \mathrm{ng} / \mathrm{L}$ for women and $34 \mathrm{ng} / \mathrm{L}$ for men $(26-28)$.

\section{Statistical Methods}

A power calculation was performed using results from a previous study using a similar technique (29), a sample size of 12 allows an $80 \%$ chance of detecting a 0.57 difference in CFR, which is considered clinically relevant. The effects of hypoglycemia on coronary flow reserve were assessed statistically by generalized linear mixed-effects modeling, with the experimental condition (hypoglycemia and euglycemia) and diabetes status as variables affecting CFR. Statistical significance was taken as a twosided $p<0.05$. Unless specifically stated, results are mean \pm standard deviation. The hsTnl data were log- 
transformed due to the skewed distribution. Heart rate, blood pressure, glucose and troponin data were analyzed using paired t-tests. Analysis of the results was performed using R stats (Version 3 for Windows and MacOS, R Foundation, USA).

\section{Results}

Study participants were all healthy young men with normal body-mass index (BMI). Baseline characteristics of both groups are provided in Table 1. During the hypoglycemia session (Table 2), the mean glucose nadir was $2.34 \pm 0.2 \mathrm{mmol} / \mathrm{L} ; 42.12 \pm 3.8 \mathrm{mg} / \mathrm{dL}$ ( $\mathrm{p}<0.001$ compared to baseline), which is sufficient to stimulate a brisk sympatho-adrenal counterregulatory response. Heart rate, systolic and mean blood pressure did not change during euglycemia in either group. During hypoglycemia, a trend was apparent towards an increase in heart rate and systolic blood pressure (BP), and a decrease in diastolic BP in both groups (Table 2). In the type 1 diabetes group, the increments in heart rate and systolic blood pressure did not reach statistical significance. In the non-diabetic group, the heart rate increased from $71 \pm 9$ beats per minute $(\mathrm{bpm})$ to $78 \pm 8 \mathrm{bpm}(\mathrm{p}=0.02)$ while the systolic BP increased from $116 \pm 11$ to $124 \pm 12 \mathrm{mmHg}(\mathrm{p}=0.001)$.

\section{Coronary Flow Velocities and Reserve}

No differences were observed between the coronary flow velocities of the group with type 1 diabetes and the non-diabetic group at baseline (Supplemental Figure 3). During hyperemia after adenosine infusion, a trend for lower coronary flow velocities was observed in people with type 1 diabetes, but this did not reach statistical significance (Supplemental Figure 3).

During euglycemia, a trend for a lower coronary flow reserve was observed in young adults with type 1 diabetes, compared to people without diabetes (3.66 \pm 0.47 versus $3.92 \pm 0.85)$, but this did not achieve statistical significance. During hypoglycaemia, coronary flow reserve trended non-significantly lower in those with type 1 diabetes than in the non-diabetic participants (3.54 \pm 0.47 versus $3.89 \pm 0.89)$ (Figure 1 ). From the generalized linear mixed model analysis, no statistical significance was reached for euglycemia or hypoglycemia affecting CFR $(p=0.31)$. No statistical significance was noted for the effect of diabetes status on CFR $(p=0.23)$.

\section{High-sensitivity Cardiac Troponin I}

The hs-cTnl values were in a skewed distribution and were therefore log transformed for statistical analysis. No changes were observed in plasma high-sensitivity cardiac troponin I concentrations during euglycemia or hypoglycemia during the recovery phase in either group (Figure 2).

\section{Discussion}

The present study used a well validated, non-invasive method to examine the effect of acute hypoglycemia on real-time coronary arterial flow in adults with and without type 1 diabetes, with the 
coronary flow ratio (CFR) being measured using transthoracic Doppler echocardiography. During acute hypoglycemia, young adult males with type 1 diabetes had a trend of lower coronary flow reserve compared with an age-matched group of non-diabetic males. The modest decline in CFR was well tolerated in young men with type 1 diabetes who were otherwise healthy and had no evidence either of microvascular complications or of coronary heart disease; normal coronary reserve was maintained.

The direct effects of hypoglycemia on cardiac function have proved difficult to elucidate as insulin per se exerts direct effects on the heart. Fisher et al (9) showed that administration of insulin caused an immediate increase in left ventricular ejection fraction and provoked sympathetic activation, both of which occurred before any fall in blood glucose. As blood glucose declined progressively, these responses became more pronounced, with the maximal changes coinciding with the glucose nadir (9). A strength of the present study was the ability to use a non-invasive real-time assessment of coronary flow reserve during acute hypoglycemia. By using a hyperinsulinaemic glucose clamp it was possible to compare CFR during euglycemia and hypoglycemia, and between type 1 diabetes and the non-diabetic state. The changes observed are therefore related to the low blood glucose and to counterregulatory mechanisms, and not to the intravenous infusion of insulin per se. Furthermore, this study provides a direct assessment of coronary vasomotor function which excludes other potential confounders such as hypertension or microvascular disease.

The main limitation of the study is the small sample size. While this was in part a consequence of the robust exclusion criteria, the demanding study design also limited recruitment of potential participants, specifically because of the use of adenosine to induce maximal hyperemia of the coronary blood vessels. The rationale for using adenosine was its short half-life, which meant that the CFR values from one measurement to the next would not be confounded by residual effects of adenosine. The disadvantage of this approach is that adenosine is often poorly tolerated because it induces unpleasant side-effects of chest tightness and facial flushing, which diminishes the willingness of volunteers to participate. In addition, the glucose clamp procedure is onerous and had to be repeated at least two weeks apart, which was a further limitation to recruitment.

A previous investigation by Rana and colleagues (30), which to our knowledge is the only other study to have explored the effect of acute hypoglycemia on the myocardial circulation, used sequential hyperinsulinemic glucose clamps and dipyridamole-induced stress echocardiography to measure myocardial blood flow reserve during euglycemia and acute hypoglycemia in adults of both sexes, 28 with, and 19 without type 1 diabetes (30). The age range was wider than in the present study and included people with microvascular disease. Hypoglycemia induced a significant fall in myocardial blood flow reserve in both groups, with lower values being observed in the group with type 1 diabetes at all times of measurement. A statistically significant association was observed with the presence of microvascular complications. In contrast to the present study design, no time interval was allowed between the initial euglycemia and the subsequent induction of hypoglycemia, so that myocardial blood flow reserve rose during the period of protracted euglycemia, which may have influenced the effect on the subsequent hypoglycemia (30). In addition, the order of the euglycemic and hypoglycemic clamps was 
not randomized, which may have introduced observer bias and an order effect. Furthermore, the long halflife of dipyridamole might have influenced the results. The present study may therefore have provided a more direct model of coronary flow reserve with fewer confounding factors such as the presence of microvascular disease and a possible residual effect of dipyridamole.

In the present study no significant change in CFR was observed during hypoglycemia. While a nonsignificant trend towards a lower CFR was observed in the participants with type 1 diabetes during euglycemia, a trend towards a decline in CFR was also observed during hypoglycemia, consistent with previous observations (17). The lowest CFR values during hypoglycemia were observed in the participants with type 1 diabetes. The increments in heart rate and systolic blood pressure in the group with type 1 diabetes did not achieve statistical significance (Table 2), which was unexpected with this degree of hypoglycemia. The small sample size may not have allowed sufficient sensitivity to detect small variations in pulse and blood pressure. An alternative interpretation is that some participants with type 1 diabetes may have had some degree of autonomic dysfunction or a diminished catecholamine response to hypoglycemia, which contributed to the modest haemodynamic changes and the lower CFR values observed in the group with type 1 diabetes. As formal assessment of autonomic function in the participants was not made nor were plasma catecholamines measured, this possibility cannot be excluded.

A Danish study using non-invasive cardiac magnetic resonance imaging has reported that myocardial blood flow reserve was higher at rest and lower during vasodilatory stress in people with type 2 diabetes compared with non-diabetic controls (31). Impaired myocardial blood flow reserve was associated with microvascular complications (albuminuria and retinopathy) of diabetes. The present study explicitly excluded people with overt microvascular disease; it is possible that the development of cardiac microangiopathy may underlie an abnormal response to hypoglycaemia in type 1 diabetes (30).

While no change in the highly sensitive troponin values was observed during acute hypoglycemia, this was measured in close temporal proximity to the blood glucose nadir. It is possible that measurement in the immediate 'recovery' stage was made too early to detect a rise in plasma troponin and exclude evidence of myocardial insult.

The results of the present study imply that any putative cardiac harm of hypoglycemia is unlikely to be mediated solely through coronary vasomotor dysfunction. Other potentially harmful factors associated with hypoglycemia may be required, such as the promotion of pro-thrombotic mechanisms $(32,33)$, endothelial abnormalities (11), or altered cardiac electrical conduction (34,35)'. Recent randomised controlled trials (RCTs) that did not target strict glycaemic control but used drugs with a low risk of hypoglycemia have shown beneficial cardiovascular outcomes $(36,37)$. This is in direct contrast to previous RCTs, in which very strict glycaemic control was pursued and the incidence of severe hypoglycemia was high (10). These findings suggest that avoidance of hypoglycaemia is important to achieve cardiovascular benefit. 


\section{Conclusions}

Although in the present study hypoglycaemia had no effect on markers of ischemia, a small reduction in CFR was apparent during hypoglycemia, with the lowest numerical value occurring in young adults with type 1 diabetes during hypoglycaemia. Further larger studies that include female participants are required to confirm or refute this observation. If the present observation of a lower CFR is confirmed, this would raise concern that hypoglycemia may promote myocardial ischemia in older people with diabetes who have established coronary heart disease. While coronary blood flow should be examined during hypoglycemia in people with type 2 diabetes who have a greater risk of cardiovascular disease, this was not undertaken because of the potential cardiac risk to such participants. The present study should be repeated in a larger number of people with type 1 diabetes, using a more tolerable form of investigation and a real time biomarker of cardiac injury. As population studies have shown an association between severe hypoglycemia and cardiovascular risk $(5,38)$ more mechanistic studies are required to elucidate potential reasons for this association.

\section{Declarations}

\section{Ethics Approval}

The study was conducted with informed written consent of all subjects, the approval of the Lothian Medical Research Ethics committee, and in accordance with the Declaration of Helsinki.

\section{Consent for publication:}

Not applicable

\section{Availability of data and materials statement:}

The datasets used and/or analysed during the current study are available from the corresponding author on reasonable request.

\section{Funding}

The study was funded by the Scottish Chief Scientist Office (Grant number CZB/4/721). DEN is supported by the British Heart Foundation (CH/09/002, RG/16/10/32375, RE/18/5/34216) and a Wellcome Trust Senior Investigator Award (WT103782AIA).

\section{Competing interests:}

The authors disclose no conflicts of interest in this study.

\section{Statement of Contributions:}


RMN, ACW, NNL and NLM contributed to acquisition, analysis and interpretation of the data and to preparation and critical revision of the manuscript. KKL contributed to analysis of the data and preparation of the manuscript. DEN, CCL, AJG and BMF contributed to the study concept and design and to the preparation and critical revision of the manuscript. RMN is the guarantor of this work, had full access to the data, and takes responsibility for the integrity of the data and the accuracy of the data analysis.

\section{Acknowledgements:}

We express our gratitude to the volunteers and to the nursing and support team at the Wellcome Trust Clinical Research Facility at the Royal Infirmary of Edinburgh for their help in the study. In addition, we acknowledge the invaluable assistance of the Scottish Diabetes Research Network and the clerical staff at the Department of Diabetes at the Royal Infirmary of Edinburgh.

\section{List Of Abbreviations}

BMI: $\quad$ Body Mass Index

BP: blood pressure

BPM: beats per minute

CFR: coronary flow reserve

HbA1c: glycated hemoglobin

hs-cTnl: high-sensitivity cardiac troponin I

LAD: left anterior descending

PROBE: prospective, randomized, open-label, blinded endpoint study

RCTs: randomized controlled trials

Vmax: maximum velocity

\section{References}

1. Zimmet PZ, Magliano DJ, Herman WH, Shaw JE. Diabetes: a 21st century challenge. Lancet Diabetes Endocrinol. 2014;2:56-64.

2. Rawshani A, Gudbjörnsdottir S. Mortality and Cardiovascular Disease in Type 1 and Type 2 Diabetes. N Engl J Med. 2017;377:300-301.

3. Gerstein HC, Miller ME, Byington RP, . Effects of intensive glucose lowering in type 2 diabetes. N Engl J Med. 2008;358:2545-2559. 
4. Duckworth W, Abraira C, Moritz T, Goff DC Jr, Bigger JT, Buse JB, Cushman WC, Genuth S, Ismail-Begi F, Grimm RH Jr, Probstfield JL, Simons-Morton DG, Friedwald WT. Glucose control and vascular complications in veterans with type 2 diabetes. N Engl J Med. 2009;360:129-139.

5. Goto A, Arah OA, Goto M, Terauchi Y, Noda M. Severe hypoglycaemia and cardiovascular disease: systematic review and meta-analysis with bias analysis. BMJ 2013;347:f4533.

6. Yeh JS, Sung SH, Huang HM, Yang HL, You LK, Chuang SY, Huang PC, Hsu PF, Cheng HM, Chen CH. Hypoglycemia and risk of vascular events and mortality: a systematic review and meta-analysis. Acta Diabetol. 2016;53:377-392.

7. Wright RJ, Frier BM. Vascular disease and diabetes: is hypoglycaemia an aggravating factor? Diabetes Metab Res Rev. 2008;24:353-363.

8. Hilsted J, Bonde-Petersen F, Norgaard MB, Greniman M, Christensen NJ, Parving HH, Suzuki M. Haemodynamic changes in insulin-induced hypoglycaemia in normal man. Diabetologia. 1984;26:328-332.

9. Fisher BM, Gillen G, Dargie HJ, Inglis GC, Frier BM. The effects of insulin-induced hypoglycaemia on cardiovascular function in normal man: studies using radionuclide ventriculography. Diabetologia. 1987;30:841-845.

10. Frier BM, Schernthaner G, Heller SR. Hypoglycemia and cardiovascular risks. Diabetes Care. 2011;34 Suppl 2:S132-137.

11. Joy NG, Tate DB, Younk LM, Davis SN. Effects of Acute and Antecedent Hypoglycemia on Endothelial Function and Markers of Atherothrombotic Balance in Healthy Humans. Diabetes. 2015;64:25712580.

12. Hirata K, Amudha K, Elina R, Hozumi T, Yoshikawa J, Homma S, Lang CC . Measurement of coronary vasomotor function: getting to the heart of the matter in cardiovascular research. Clin Sci (Lond). 2004;107:449-460.

13. Hirata K, Kadirvelu A, Kinjo M, Sciacca R, Sugioka K, Otsuka R, Choy A, Chow SK, Yoshiyama M, Yoshikawa J, Homma S, Lang CC. . Altered coronary vasomotor function in young patients with systemic lupus erythematosus. Arthritis Rheum. 2007;56:1904-1909.

14. Baumgart D, Haude M, Liu F, Ge J, Goerge G, Erbel R. Current concepts of coronary flow reserve for clinical decision making during cardiac catheterization. Am Heart J. 1998;136:136-149.

15. Hozumi T, Yoshida K, Akasaka T, Asami Y, Ogata Y, Takagi T, Kaji S, Kawamoto T, Ueda Y, Morioka S. Noninvasive assessment of coronary flow velocity and coronary flow velocity reserve in the left anterior descending coronary artery by Doppler echocardiography: comparison with invasive technique. J Am Coll Cardiol. 1998;32:1251-1259.

16. Okayama H, Sumimoto T, Hiasa G, Morioka N, Yamamoto K, Kawada H. Usefulness of an echocontrast agent for assessment of coronary flow velocity and coronary flow velocity reserve in the left anterior descending coronary artery with transthoracic doppler scan echocardiography. Am Heart J. 2002;143:668-675. 
17. Pitkanen OP, Nuutila P, Raitakari OT, Rönnemaa T, Koskinen PJ, lida H, Lehtimäki TJ, Laine HK, Takala T, Viikari JS, Knuuti J . Coronary flow reserve is reduced in young men with IDDM. Diabetes. 1998;47:248-254.

18. Akasaka T, Yoshida K, Hozumi T, Takagi T, Kaji S, Kawamoto T, Morioka S, Yoshikawa J . Retinopathy identifies marked restriction of coronary flow reserve in patients with diabetes mellitus. J Am Coll Cardiol. 1997;30:935-941.

19. Mills NL, Churchhouse AM, Lee KK, Anand A, Gamble D, Shah AS, Paterson E, MacLeod M, Graham C, Walker S, Denvir MA, Fox KA, Newby DE. Implementation of a sensitive troponin I assay and risk of recurrent myocardial infarction and death in patients with suspected acute coronary syndrome. JAMA. 2011;305:1210-1216.

20. Chapman AR, Shah ASV, Lee KK, Anand A, Francis O, Adamson P, McAllister DA, Strachan FE, Newby DE, Mills NL. Long-Term Outcomes in Patients With Type 2 Myocardial Infarction and Myocardial Injury. Circulation. 2018;137:1236-1245.

21. Hirata K, Shimada K, Watanabe H, Muro T, Yoshiyama M, Takeuchi K, Hozumi T, Yoshikawa J. Modulation of coronary flow velocity reserve by gender, menstrual cycle and hormone replacement therapy. J Am Coll Cardiol. 2001;38:1879-1884.

22. Davis SN, Fowler S, Costa F. Hypoglycemic counterregulatory responses differ between men and women with type 1 diabetes. Diabetes. 2000;49:65-72.

23. Gold AE, MacLeod KM, Frier BM. Frequency of severe hypoglycemia in patients with type I diabetes with impaired awareness of hypoglycemia. Diabetes Care. 1994;17:697-703.

24. Graveling AJ, Deary IJ, Frier BM. Acute hypoglycaemia impairs executive cognitive function in adults with and without type 1 diabetes. Diabetes Care. 2013;36:3240-3246

25. DeFronzo RA, Tobin JD, Andres R. Glucose clamp technique: a method for quantifying insulin secretion and resistance. Am J Physiol. 1979;237:E214-223.

26. Shah AS, Griffiths M, Lee KK, McAllister DA, Hunter AL, Ferry AV, Cruikshank A, Reid A, Stoddart M, Strachan F, Walker S, Collinson PO, Apple FS, Gray AJ, Fox KA, Newby DE, Mills NL. High sensitivity cardiac troponin and the under-diagnosis of myocardial infarction in women: prospective cohort study. BMJ. 2015;350:g7873.

27. Shah AS, Anand A, Sandoval Y, Lee KK, Smith SW, Adamson PD, Chapman AR, Langdon T, Sandeman D, Vaswani A, Strachan FE, Ferry A, Stirzaker AG, Reid A, Gray AJ, Collinson PO, McAllister DA, Apple FS, Newby DE, Mills NL. High-sensitivity cardiac troponin I at presentation in patients with suspected acute coronary syndrome: a cohort study. Lancet. 2015;386(10012):2481-2488.

28. Shah ASV, Ferry AV, Mills NL. Cardiac Biomarkers and the Diagnosis of Myocardial Infarction in Women. Curr Cardiol Rep. 2017;19:40.

29. Hirata K, Kadirvelu A, Di Tullio M, Homma S, Choy AM, Lang CC. Coronary vasomotor function is abnormal in first-degree relatives of patients with type 2 diabetes. Diabetes Care. 2007;30:150-153.

30. Rana O, Byrne CD, Kerr D, Coppini DV, Zouwail S, Senior R, Begley J, Walker JJ, Greaves K.. Acute hypoglycemia decreases myocardial blood flow reserve in patients with type 1 diabetes mellitus and 
in healthy humans. Circulation. 2011;124:1548-1556.

31. Sorensen MH, Bojer AS, Pontopiddan JR, Broadbent DA, Plein S, Madsen PL, Gæde P. Reduced myocardial perfusion reserve is caused byincreased perfusion at rest and decreased maximal perfusion during stress. Diabetes Care, 2020; dc192172. epub ahead of print. https://doi.org/10.2337/dc19-2172

32. Wright RJ, Newby DE, Stirling D, Ludlam CA, Macdonald IA, Frier BM. Effects of acute insulin-induced hypoglycemia on indices of inflammation: putative mechanism for aggravating vascular disease in diabetes. Diabetes Care. 2010;33:1591-1597.

33. Razavi Nematollahi L, Kitabchi AE, Stentz FB, Wan JY, Larijani BA, Tehrani MM, Gozashti $\mathrm{MH}$, Omidfar K, Taheri E.. Proinflammatory cytokines in response to insulin-induced hypoglycemic stress in healthy subjects. Metabolism. 2009;58:443-448.

34. Marques JL, George E, Peacey SR, Harris ND, Macdonald IA, Cochrane T, Heller SR Altered ventricular repolarization during hypoglycaemia in patients with diabetes. Diabet Med. 1997;14:648-654.

35. Koivikko ML, Karsikas M, Salmela PI, Tapanainen JS, Ruokonen A, Seppänen T, Huikuri HV, Perkiömäki JS. Effects of controlled hypoglycaemia on cardiac repolarisation in patients with type 1 diabetes. Diabetologia. 2008;51:426-435.

36. Zinman B, Wanner C, Lachin JM, Fitchett D, Bluhmki E, Hantel S, Mattheus M, Devins T, Johansen OE, Woerle HJ, Broedl UC, Inzucchi SE. Empagliflozin, Cardiovascular Outcomes, and Mortality in Type 2 Diabetes. N Engl J Med. 2015;373:2117-2128.

37. Marso SP, Daniels GH, Brown-Frandsen K, Kristensen P, Mann JF, Nauck MA, Nissen SE, Pocock S, Poulter NR, Ravn LS, Steinberg WM, Stockner M, Zinman B, Bergenstal RM, Buse JB;. Liraglutide and Cardiovascular Outcomes in Type 2 Diabetes. N Engl J Med. 2016;375:311-322.

38. Khunti K, Davies M, Majeed A, Thorsted BL, Wolden ML, Paul SK. H

\section{Tables}

Table 1: Clinical characteristics of participants with and without type 1 diabetes 


\begin{tabular}{|c|c|c|c|}
\hline & $\begin{array}{l}\text { Participants with type } \\
\qquad \begin{array}{c}1 \text { diabetes } \\
n=17\end{array}\end{array}$ & $\begin{array}{l}\text { Participants without } \\
\qquad \begin{array}{c}\text { diabetes } \\
\mathrm{n}=10\end{array}\end{array}$ & \\
\hline Age (years) (median, range) & $30(20-35)$ & $24.5(21-33)$ & $\mathrm{p}=0.13$ \\
\hline $\operatorname{Sex}(\% \mathrm{M})$ & 100 & 100 & \\
\hline $\begin{array}{l}\text { Body Mass Index }\left(\mathrm{kg} / \mathrm{m}^{2}\right) \\
(\mathrm{mean} \pm \mathrm{SD})\end{array}$ & $25.9 \pm 2.1$ & $24.2 \pm 2.7$ & $\begin{array}{l}p= \\
0.11\end{array}$ \\
\hline $\begin{array}{l}\text { HbA1c } \\
(\% ; \mathrm{mmol} / \mathrm{mol})(\operatorname{mean} \pm \mathrm{SD})\end{array}$ & $\begin{array}{c}8 \pm 1.1 \\
(64 \pm 11)\end{array}$ & $\mathrm{n} / \mathrm{a}$ & \\
\hline $\begin{array}{l}\text { Duration of diabetes (years) } \\
\text { (median, range) }\end{array}$ & $15(2-35)$ & $\mathrm{n} / \mathrm{a}$ & \\
\hline
\end{tabular}

Table 2: Plasma glucose, heart rate, systolic, and diastolic blood pressure values during hypoglycemia and euglycemia in the groups of participants, with and without type 1 diabetes 


\begin{tabular}{|c|c|c|c|c|c|c|c|}
\hline & \multicolumn{4}{|c|}{ Euglycemic Clamp } & \multicolumn{3}{|c|}{ Hypoglycemic clamp } \\
\hline & & Baseline & Experimental & $\begin{array}{l}\mathrm{p} \\
\text { value }\end{array}$ & Baseline & Experimental & $\mathrm{p}$ value \\
\hline & $\begin{array}{l}\text { Glucose } \\
\text { (mmol/L) } \\
(\mathrm{mg} / \mathrm{dL})\end{array}$ & $\begin{array}{l}4.95 \pm 0.65 \\
89.2 \pm 11.7\end{array}$ & $\begin{array}{l}4.70 \pm 0.42 \\
84.7 \pm 7.6\end{array}$ & 0.13 & $\begin{array}{l}4.89 \pm 0.62 \\
88.1 \pm 11.1\end{array}$ & $\begin{array}{l}2.34 \pm 0.21 \\
42.2 \pm 3.6\end{array}$ & $<0.0001$ \\
\hline \multirow{3}{*}{$\begin{array}{l}\text { ple } \\
\mathrm{h} \\
\mathrm{e} \quad 1 \\
\text { betes }\end{array}$} & $\begin{array}{l}\text { Heart } \\
\text { rate } \\
(\mathrm{bpm})\end{array}$ & $73 \pm 14$ & $73 \pm 8$ & 0.68 & $66 \pm 12$ & $70 \pm 9$ & 0.2 \\
\hline & $\begin{array}{l}\text { Systolic } \\
\text { BP } \\
(\mathrm{mmHg})\end{array}$ & $127 \pm 14$ & $131 \pm 13$ & 0.58 & $127 \pm 14$ & $130 \pm 9$ & 0.43 \\
\hline & $\begin{array}{l}\text { Diastolic } \\
\text { BP } \\
(\mathrm{mmHg})\end{array}$ & $74 \pm 6$ & $71 \pm 6$ & 0.84 & $72 \pm 6$ & $70 \pm 6$ & 0.03 \\
\hline \multirow[t]{3}{*}{$\begin{array}{l}\text { ple } \\
\text { hout } \\
\text { e } 1 \\
\text { betes }\end{array}$} & $\begin{array}{l}\text { Heart } \\
\text { rate } \\
\text { (bpm) }\end{array}$ & $74 \pm 13$ & $76 \pm 10$ & 0.73 & $71 \pm 9$ & $78 \pm 8$ & 0.02 \\
\hline & $\begin{array}{l}\text { Systolic } \\
\text { BP } \\
(\mathrm{mmHg})\end{array}$ & $124 \pm 15$ & $126 \pm 13$ & 0.61 & $116 \pm 11$ & $124 \pm 12$ & 0.001 \\
\hline & $\begin{array}{l}\text { Diastolic } \\
\text { BP } \\
(\mathrm{mmHg})\end{array}$ & $69 \pm 6$ & $69 \pm 6$ & 0.52 & $67 \pm 5$ & $64 \pm 5$ & 0.2 \\
\hline
\end{tabular}

\section{Supplementary Figure Legends}

Supplemental Figure 1. Diagrammatic illustration of study protocol.

Supplemental Figure 2: Example of coronary artery flow before and after administration of adenosine. Coronary artery flow before (base pre-ad) and after (post-ad) administration of adenosine. Below the ECG tracing, corresponding to the area below the t wave and before the next QRS complex, are Doppler signals from the left anterior descending coronary artery. In the top section of the figure 'base pre-ad', the coronary Doppler signal at rest is below the green ECG line. In the bottom part of the figure ('post ad'), the 
Doppler signal during hyperemia, is increased. CFR is the coronary velocity in hyperemia (centimeters/second)/resting coronary velocity (centimeters/second)

Supplemental Figure 3: Summary of coronary flow velocities (in $\mathrm{cm} / \mathrm{s}$ ), during rest and adenosine administration, and between experimentally-induced euglycemia and hypoglycemia in participants with type 1 diabetes (blue) and people without diabetes (red).

\section{Figures}

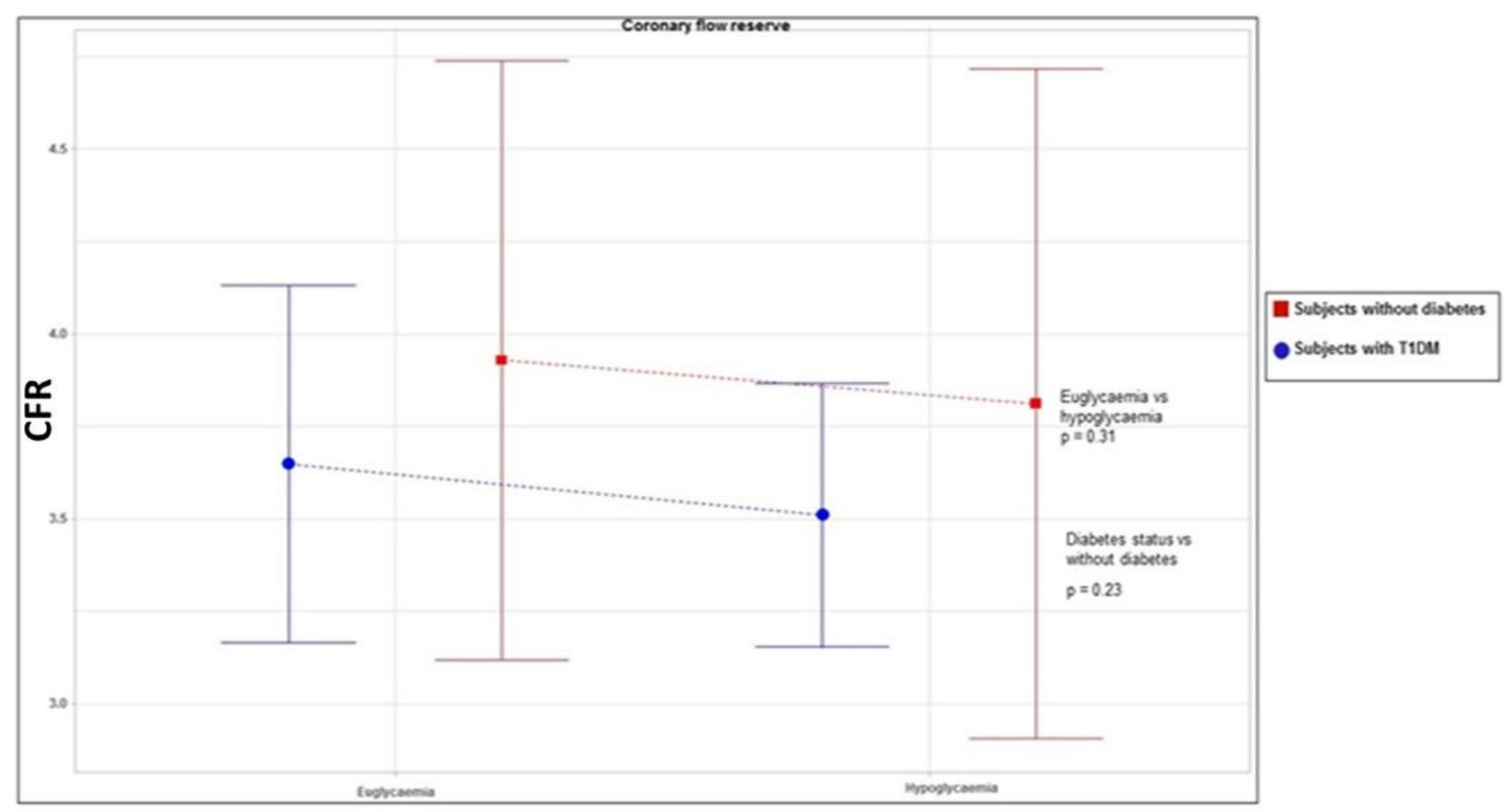

\section{Figure 1}

CFR (mean $\pm S D)$ in participants with type 1 diabetes and people without diabetes under euglycemic and hypoglycemic conditions. 


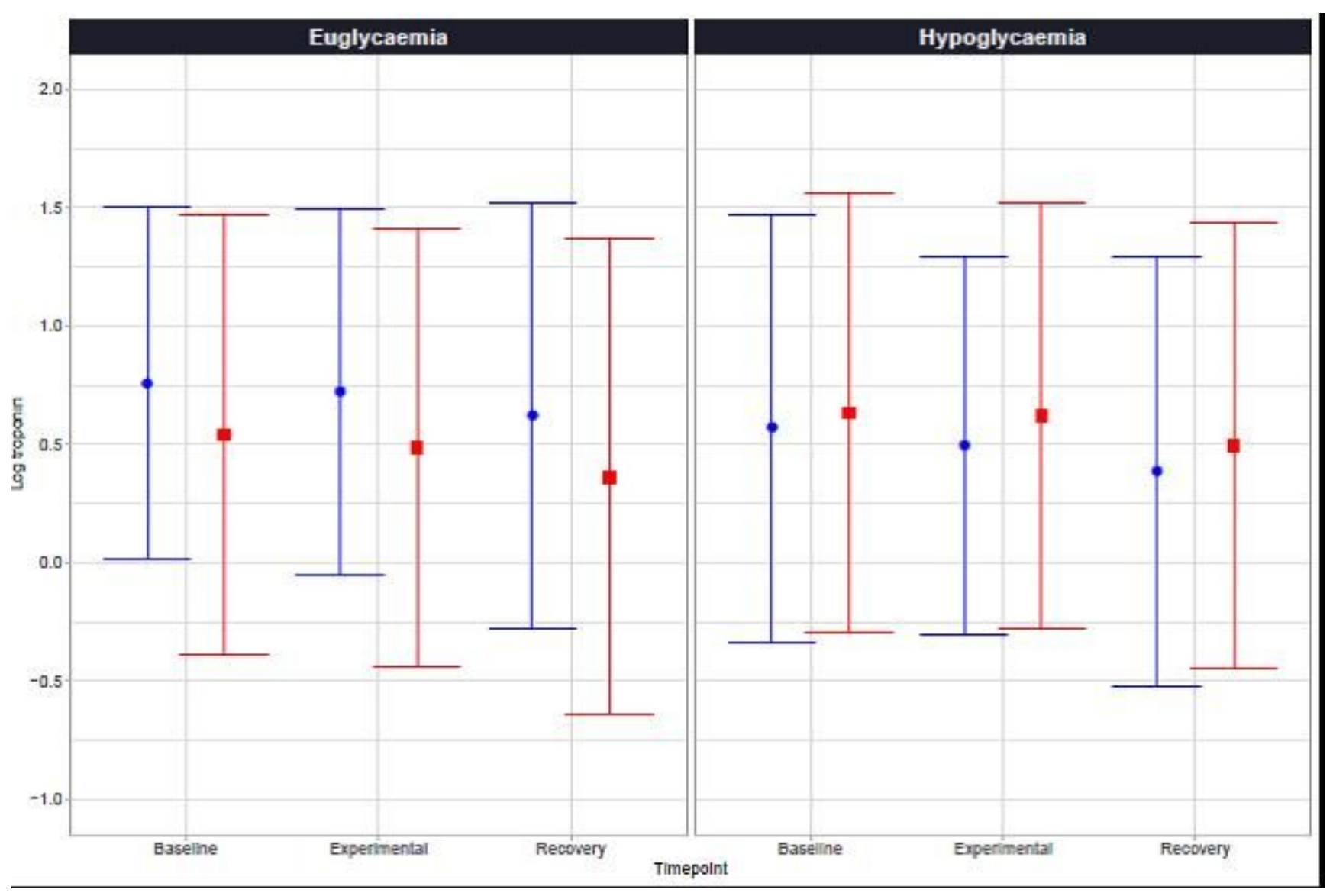

Figure 2

Log transformed highly sensitive troponin I values in $\mathrm{ng} / \mathrm{L}$, during baseline, experimental condition and recovery, for participants with type 1 diabetes and people without diabetes. Participants with type 1 diabetes are in blue and those without diabetes in red.

\section{Supplementary Files}

This is a list of supplementary files associated with this preprint. Click to download.

- SuppFig1.jpg

- STROBEchecklistClinEndo.docx

- Suppfig3.jpg

- SupFig2.jpg 